\title{
Two primary seminomas in a patient with polyorchidism
}

\author{
Abhijit Ghose, MD, MSc; ${ }^{*}$ George Rodrigues, MD, FRCPC, MSc; ${ }^{* \dagger}$ Jonathan Izawa, MD, FRCSC ${ }^{\ddagger}$
}

\begin{abstract}
We report the clinical, radiographic and pathological findings of polyorchidism and a right-sided abdominal seminoma found in a 28-year-old man who presented with cryptorchidism in childhood and who later underwent an orchiectomy for a left-sided seminoma. Pathological analysis of the abdominal tumour revealed the existence of a classic seminoma bordered by a rim of non-tumour tissue and remnants of epididymis. We propose that patients who present with cryptorchidism be assessed for polyorchidism as this might be the source of additional primary tumours.
\end{abstract}

CUAJ 2007;1(3):285-7

\section{Introduction}

Polyorchidism is rare. Several case reports and reviews have been published in which polyorchidism is shown to present in a variety of ways, including torsion, swelling, hernia or malignancy. However, to our knowledge there have not been any that have presented with bilateral malignancy, and in particular, seminoma. We describe the case of a patient originally diagnosed with a left-sided seminoma but later found to have a contralateral seminoma at an abdominally located third testicle.

\section{Case Report}

A 28-year-old man with a remote surgical history of right-sided orchiectomy for an undescended testicle during childhood presented in May 2003 with left-sided testicular pain and swelling. Ultrasound analysis of the left-sided lesion showed a hyperechoic mass that nearly replaced normal tissue in the left testicle, which was indicative of malignancy. He underwent a left radical orchiectomy in June 2003 and pathological analysis revealed a germ cell tumour with features of a seminoma. There was no invasion of the tunica albuginea or the spermatic cord, and surgical margins were negative.

The patient underwent staging with a CT scan of the head, which was negative. A CT scan of the abdomen and pelvis showed a nodular 2-cm lesion posterior to the inferior tip of the liver (Fig. 1). It was unclear whether this was an extension of hepatic tissue or a mass of unknown etiology. The patient underwent radiation treatment to the pelvic and para-aortic nodes to a dose of 25 Gy in 20 fractions in July 2003, followed by a magnetic resonance imaging (MRI) study of his abdomen in August. This once again showed the above-mentioned lesion and a fine needle aspiration performed after the repeat imag- ing was negative for malignancy. Thus the lesion was not investigated further at this point in time.

The patient had a routine follow up in December 2003, at which time he was well. A CT scan of his abdomen was unremarkable, except for the nodule juxtaposed to the liver. In March 2004 a radiologist was asked to review all of his imaging in an effort to ascertain the nature of this lesion. The opinion at the time was that this could be an exophytic hemangioma, although a malignancy could not be ruled out.

In April 2004 an ultrasound-guided needle biopsy performed to re-examine this lesion showed that the mass had grown to $3.9 \times 3.3$ $\times 2.4 \mathrm{~cm}$. Additionally, the cores contained malignant tumour, with features of classic seminoma. This was adjacent to non-tumour testicular tissues, including atrophic seminiferous tubules, fragments of skeletal muscle and fibrocollagenous hyaline tissue.

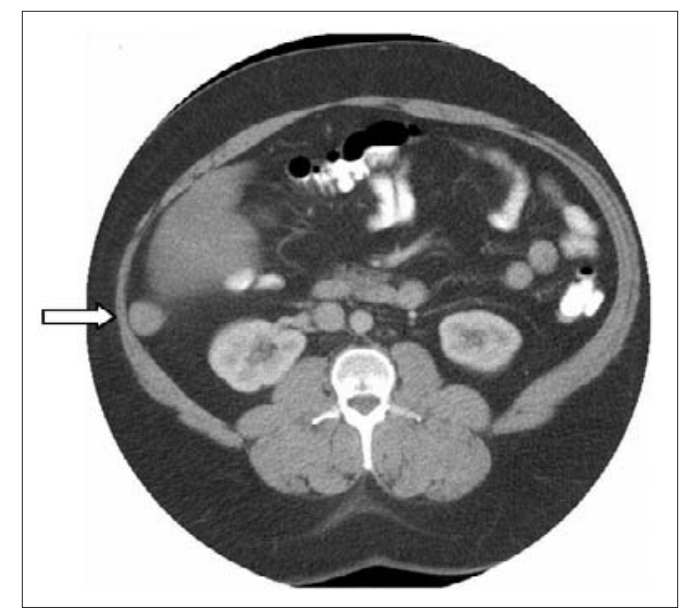

Fig. 1. A CT scan of the chest and abdomen performed in June of 2003 following an orchiectomy for a left-sided seminoma. The CT scan was remarkable for a nodular 2-cm lesion (arrow) of unknown etiology posterior to the inferior tip of the liver. 
The patient underwent a laparoscopic excision of this parahepatic mass in July of 2004. Grossly, the mass was attached to fibroadipose tissue at one of its poles, with testicular appendices noted near the site of the attachment. On sectioning, there was a homogeneous, creamy white surface with dilated and congested blood vessels (Fig. 2). Microscopic analysis revealed a classic seminoma with scattered dystrophic calcification and no nonseminomatous components. There was no extratesticular extension of the tumour, and there was evidence of non-tumour testis forming a rim around the tumour, with areas of hemorrhage. This residual atrophic testis was separated from the tumour by a thin fibrous capsule. In addition, within the area of the normal testis, there were occasional tubules containing atypical cells consistent with intratubular germ cell neoplasia. Further, at the periphery of the testis there were some tubular structures resembling rete testis. Pathology of the fibroadipose tissue attached to the pole of this testis as well as the testicular appendices revealed portions of epididymis.

In August 2004 the patient was well. He was started on oral testosterone by the endocrinology service and in consultation with the radiation oncologist, medical oncologist and urologist, surveillance was assessed to be the best option from this point onward, with the option of chemotherapy in the event of recurrence. The patient has been followed every 3 months with a CT scan of

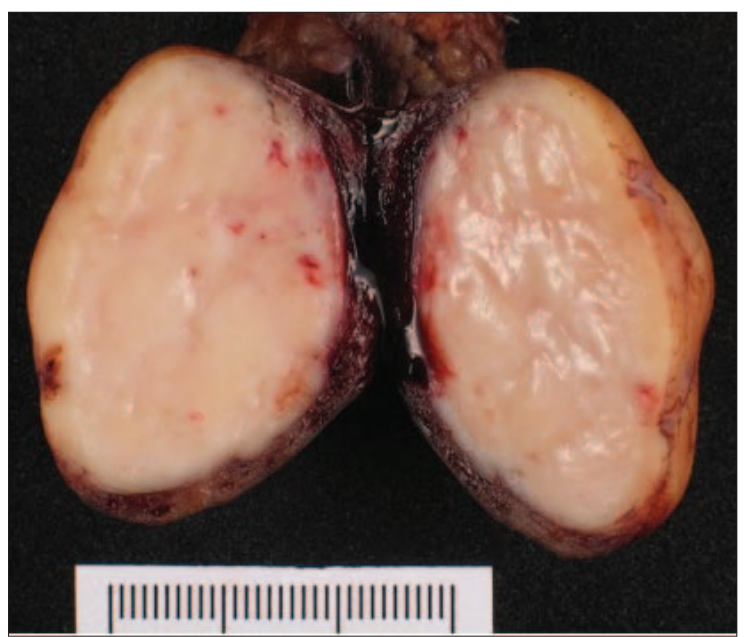

Fig. 2. View of the parahepatic mass following excision and sectioning. Microscopic analysis reveals this to be a classic seminoma with no non-seminomatous components. In addition, there is a rim of normal, non-tumour testis around the seminoma. his chest and abdomen since August 2004, and he has been well with no recurrence of disease.

\section{Discussion}

Factors controlling the embryological descent of the testes are not entirely clear. Testicular descent occurs in 2 stages: the transabdominal phase and the inguinoscrotal phase. The transabdominal phase starts at about 8-15 weeks of development and at this time the testis is attached to the posterior abdominal wall by the urogenital mesentery. ${ }^{1,2}$ In the male, the caudal end of this attachment becomes the caudal genito-inguinal ligament, also known as the gubernaculum. The gubernaculum begins to enlarge under the control of a newly described hormone, Insulin-like hormone 3 (Insl3), that is made by the Leydig cells. ${ }^{1,3}$ An existing cranial suspensory ligament also begins to regress under the influence of testosterone.

During the inguinoscrotal phase (at 25-35 weeks) the gubernaculum grows out from the abdominal wall and physically migrates into the scrotum. ${ }^{1,4}$ Inside the gubernaculum, the processus vaginalis enlarges to create an extension of the abdominal cavity to the scrotum. ${ }^{2}$ The direction of migration of the gubernaculum (followed by the testes) occurs along the genitofemoral nerve and is thought to be under the control of calcitonin gene related peptide (CGRP). ${ }^{1,5}$

Congenital cryptorchidism is caused by the failure of gubernacular migration to the scrotum. In contrast, acquired cryptorchidism is caused by the failure of spermatic cord elongation, usually later in life, between the ages of 5 and 10 years. Polyorchidism is defined as 3 or more testes. It is an uncommon anomaly thought to arise from duplication of the genital ridge during embryological development. Although rare, there have been several reviews in the literature. ${ }^{6-8}$ Individual case reports have shown polyorchidism to present as a painless mass, ${ }^{9}$ torsion,, $710-14$ inguinal hernia ${ }^{15}$ or malignancy. ${ }^{16}$ The patient's age at presentation has been variable and treatment is generally surgical. ${ }^{17}$

We present the case of a young man originally thought to have a cryptorchid testicle and a contralateral seminoma. Subsequent follow-up revealed another primary seminoma arising from a third ectopic testicle located in the patient's abdomen. We propose that patients who present with cryptorchidism be assessed for polyorchidism by $\mathrm{CT}$ 
scan or MRI of the abdomen and pelvis, and serum testosterone, as polyorchidism might be a source of rare additional primary germ cell tumours.

\section{Conclusion}

This case highlights the importance of considering polyorchidism in patients who present with a cryptorchid testicle in childhood. While this is a known risk factor for seminoma in the contralateral testicle, it is not known whether it is also a risk factor for seminoma in an ectopically located testicle that may be present owing to a developmental anomaly. Indeed, the small numbers of patients who present with polyorchidism make the association between cryptorchidism, polyorchidism and ectopic seminoma difficult to determine. We recommend that patients who do present with cryptorchidism be closely assessed to determine whether they have a polyorchid testicle, as this may be the site of a new primary seminoma.

From the *Department of Radiation Oncology, London Regional Cancer Program, London, Ont., the †Department of Epidemiology and Biostatistics, University of Western Ontario, London, Ont., and the łDepartments of Surgery and Oncology, Division of Urology, London Health Sciences Centre-Victoria Hospital, London, Ont.

This article has been peer reviewed.

Competing interests: None declared.

\section{References}

1. Hutson JM, Hasthorpe S. Abnormalities of testicular descent. Cell Tissue Res 2005;
332:155-8.

2. Sadler TW. The urogential system. In: Langman's medical embryology. 7th edition. Patricia Coryell, editor. Baltimore (MD): Wilkins and Wilkins; 1995. p 305-8.

3. Nef S, Parada LF. Cryptorchidism in mice mutant for InsI3. Nat Genet 1995;22:295-9.

4. Heyns CF. The gubernaculum during testicular descent in the human fetus. J Anat 1987; 153:93-112.

5. Shenker NS, Huynh J, Farmer PJ, et al. A new role for androgen in testicular descent: permitting gubernacular cell proliferation in response to the neuropeptide, calcitonin gene-related peptide. J Pediatr Surg 2006;41:407-12.

6. Lawrentschuk N, MacGregor RJ. Polyorchidism: a case report and review of the literature. ANZ J Surg 2006;74:1130-2.

7. Shah SN, Miller BM, Geisler E. Polyorchidism discovered as testicular torsion. Urology 2006:39:543-4.

8. Thum G. Polyorchidism: case report and review of the literature. J Urol 1991;145:370-2.

9. Amodio JB, Maybody M, Slowotsky C, et al. Polyorchidism: report of 3 cases and review of the literature. J Ultrasound Med 2004;23:951-7.

10. Ferro F, lacobelli B. Polyorchidism and torsion. A lesson from 2 cases. J Pediatr Surg 2005; 40:1662-4.

11. Hwang S, Aronoff DR, Leonidas JC. Case 82: Polyorchidism with torsion. Radiology 2005;235:433-5

12. Sozer IT, Kamberoglu H, Yucebas E. Polyorchidism, bilateral double testis and unilat eral testicular torsion. Br J Urol 1989;64:546-7.

13. Gandia VM, Arrizabalaga M, Leiva 0 , et al. Polyorchidism discovered as testicular torsion associated with an undescended atrophic contralateral testis: a surgical solution. J Urol 1987; 137:743-4.

14. Scott KW. A case of polyorchidism with testicular teratoma. J Urol 1980;124:930-1.

15. Ozok G, Taneli C, Yazici $M$, et al. Polyorchidism: a case report and review of the literature. Eur J Pediatr Surg 1992;2:306-7.

16. Kulkarni IN, Bhansali MS, Tongaonkar HB, et al. Carcinoma in the third testis in a case of polyorchidism and persistent mullerian structure syndrome. Eur Urol 1992;22:174-6.

17. Irwin CE Jr, Shafer MA, Mosciki AB. The adolescent patient. In: Rudolph's pediatrics. 21st ed. Rudolph C and Rudolph A, editors. New York (NY): McGraw Hill; 2003. Table $3-13$.

Correspondence: Dr. George Rodrigues, Department of Radiation Oncology, London Regional Cancer Program, London Health Sciences Centre, London ON N6A 4L6; fax 519 685-8736; george.rodrigues@lhsc.on.ca 